\title{
Correction: Peripapillary retinal nerve fiber layer and ganglion cell complex degeneration in Egyptian patients with bipolar disorder
}

Dalia H. Khalil ${ }^{1}$ Mohamed M. Said ${ }^{2}$

Published online: 3 June 2019

(c) The Royal College of Ophthalmologists 2019

\section{Correction to: Eye}

https://doi.org/10.1038/s41433-019-0403-5

Published online: 29 March 2019

These authors contributed equally: Dalia H. Khalil, Mohamed M. Said

The original article can be found online at https://doi.org/10.1038/ s41433-019-0403-5.

Dalia H. Khalil

Daliahamed_76@yahoo.com

1 Ophthalmology Department, Faculty of Medicine, Cairo University, Giza, Egypt

2 Ophthalmology Department, Faculty of Medicine, Fayoum University, Faiyum, Egypt
Since the online publication of the above article, the authors have requested a change to the author list. The full correct author list is:

Dalia H Khalil, Mohamed M. Said

The authors apologise for any convenience caused by this error. 